\title{
EFFECT OF VIBRO-ABRASIVE MACHINING ON THE QUALITY OF THE ZINC COATINGS
}

\author{
${ }^{1}$ Sylwia WĘGRZYNKIEWICZ, ${ }^{2}$ Maciej HAJDUGA \\ ${ }^{1}$ BELOS - PLP S.A., Bielsko-Biała, Poland, EU, sylwia.wegrzynkiewicz@belos-plp.com.pl \\ ${ }^{2}$ Academy of Technology and Humanities, Bielsko-Biała, Poland, EU, mhajduga@ath.bielsko.pl
}

https://doi.org/10.37904/metal.2019.732

\section{Abstract}

The purpose of the work was to assess the influence of the vibro-abrasive treatment on the quality of the zinc coating. The use of vibro-abrasive finishing in the production process of fittings for overhead power line is designed to improve the aesthetics of the coating by eliminating zinc beads and burrs, as well as shorten the time of detecting the details on the production. Research was focused on ball-eye links, made of steel grade $41 \mathrm{Cr} 4$. The vibro-abrasive machining was carried out in an $\mathrm{R} 320$ device using porcelain polishing fittings type $\mathrm{R} 8 / 10$ and technological liquid type COMPUND FC after hot dip galvanizing.

Comparative tests were conducted for samples without and with vibro-abrasive machining. The effects were evaluated on the basis of metallographic analysis, evaluation of surface roughness and topography, microhardness measurement and corrosion tests.

It was found that the use of additional treatment after galvanizing improves aesthetic features of products and does not significantly reduce its corrosion resistance.

Keywords: Vibro-abrasive machining, hot dip galvanizing, zinc coating, corrosion resistance

\section{INTRODUCTION}

According to EN ISO 1461 the primary purpose of the galvanized coating is to protect the iron or steelwork against corrosion. Considerations related to aesthetics or decorative features should be secondary. The significant surfaces of all the hot dip galvanized articles shall be free from nodules, blisters, roughness and sharp points (if either can cause injury) and uncoated areas [1]. The zinc coating should be free of flux residues. Lumps and zinc ash shall not be permitted where they might affect the intended use of the hot dip galvanized article or its corrosion resistance requirement. It should be noted that "roughness" and "smoothness" are relative terms. In practice, it is not possible to establish a definition of appearance and finish covering all requirements [1-3].

The requirements for hot dip galvanized products are higher each year. It is particularly important for centrifuged forgings. During the centrifugation process, the excess zinc is randomly cast on the details in the centrifuge basket. Consequently, gouges, burrs, sharp points that reduce the quality of the product are formed on the galvanized products [3]. Finaly, it is necessary to check the galvanized batch of products and to improve the gaps. Manual finishing and cleaning of the surface of the details is extremely time-consuming, what increases the cost of these operations. This situation is important for complex parts in mass production.

The desire to reduce the production costs and stabilize production in terms of quality, requires the search for effective methods of finishing. One of the possibilities to propose finishing methods is vibro-abrasive machining [4]. This process is becoming more widely used, especially in the production of large-scale products with small dimensions [4-7].

Vibro-abrasive machining consists in removing small excess material, as a result of relative displacements of abrasive shapes in relation to workpieces. In the working bowl of the device there are details, fittings, water and process fluid that are set in motion by the vibratory drive system. This results in permanent mutual movement of media and processed details. During the interactions of workpieces with abrasive profiles, the 
orientation of abrasive grains relative to the main kinematic directions at the moment of contact with the workpiece is random. This type of smoothing is often carried out in the presence of aqueous solutions that support the process. Manufacturers do not reveal the chemical composition of these substances only inform about the scope of their applications $[6,7]$.

The purpose of the work was to assess the influence of the vibro-abrasive treatment on the corrosion resistance of the zinc coating. The use of vibro-abrasive finishing in the production process of fittings for overhead power line is designed to improve the aesthetics of the coating by eliminating zinc beads and burrs, as well as shorten the time of detecting the details on the production.

\section{OWN RESEARCH}

\subsection{Tested material}

Research was focused on ball-eye links, made of steel grade $41 \mathrm{Cr} 4$, used in fittings for overhead power lines. General appearance of tested link is presented in Figure 1. An example of a ball-eye link is shown in Figure 2.

a)

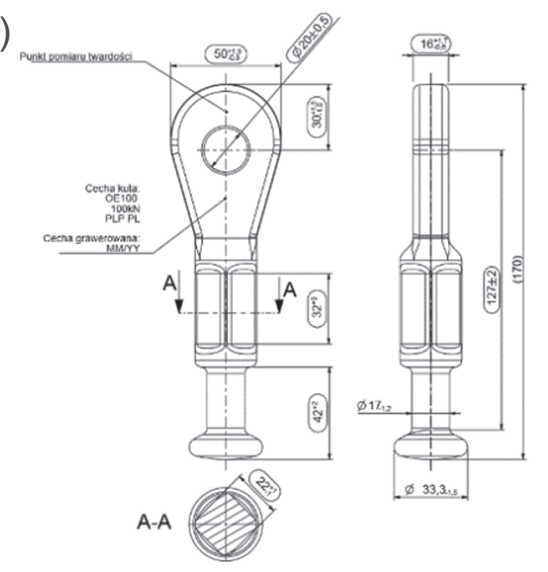

Figure 1 Dimensions of the tested ball-eye link
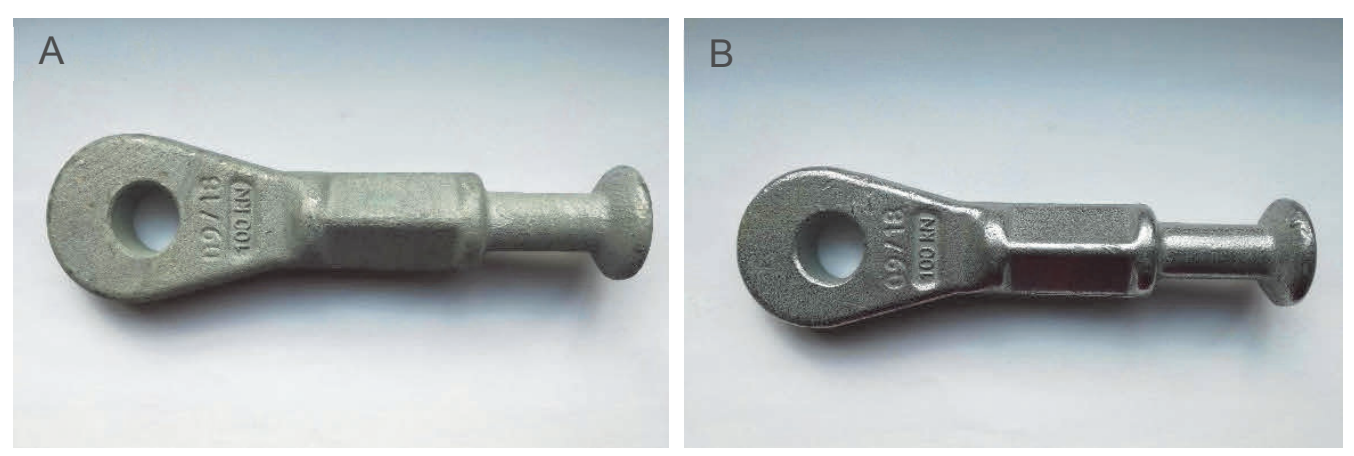

Figure 2 General appearance of tested ball-eye links: A- in initial state, B- after vibro-abrasive machining

\subsection{Preparation of material for tests}

Before hot dip galvanizing ball-eye links were shodblasted with steel-shot GL 40 . Then, the links were etched in $\mathrm{HCl}$ solution (acid concentration $9.8 \%$ ), rinsed in water and fluxed in Tibflux60 (pH 4.8). In the next stage, the hot dip galvanizing proces was carried out acc. To ISO 1461 in temp. $455^{\circ} \mathrm{C}$, dipping time $2 \mathrm{~min}$. The zinc bath chemical composition was as follows (wt\%): $99.874 \mathrm{Zn}, 0.0431 \mathrm{Ni}, 0.0479 \mathrm{Bi}, 0.00020 \mathrm{Al}, 0.0273 \mathrm{Fe}$, $0.0009 \mathrm{Sn}, 0.0051 \mathrm{Cu}, 0.0012 \mathrm{Cd}$. After hot dip galvanizing, the excess zinc was centrifuged on a stationary centrifuge. 
After hot dip galvanizing and centrifuging links were divided into two group A and B. For Group A a standard procedure was applied, additional machining was not performed. A vibro-abrasive machining was carried out for the links from Group B.

The vibro-abrasive treatment was conducted in the $R 320$ device using porcelain polishing fittings type $R$ 8/1 and technological liquid type COMPUND FC. The parameters of technology were developed by ZJG Kooperacja Przemysłowo-Handlowa from Gliwice and they were covered by secrecy.

\section{METHODOLOGY AND RESULTS RESEARCH}

\subsection{The surface roughness and topography assessment}

Mahr Perthometrer with the Concept v. 7.0 software was used to measure surface roughness and topography (head: MFW-250, a mating blade with a radius of $2 \mu \mathrm{m}$ and an angle of $90^{\circ}$ ).

The topography measurement parameters were as follows: elementary section- $0.25 \mathrm{~mm}$, measuring section$1.25 \mathrm{~mm}$, maping section- $1.75 \mathrm{~mm}$, number of episodes- 5 , number of cross-sections- 351 , number of points in the $\mathrm{X}$ axis $\mathrm{Nx}=5000$. Selected examples of surface topography of tested links are presented in Figure 3.

The surface roughness was described according to ISO 4287 and ISO 13565-2 standards [8,9]. The average values of presented parameters to describe Ra, Rp and Rv may be analysed in Table 1, where Ra - it is an arithmetic mean of profile ordinates, Rp - height of highest peak of the profile, Rv - depth of the lowest valley of the profile.

A

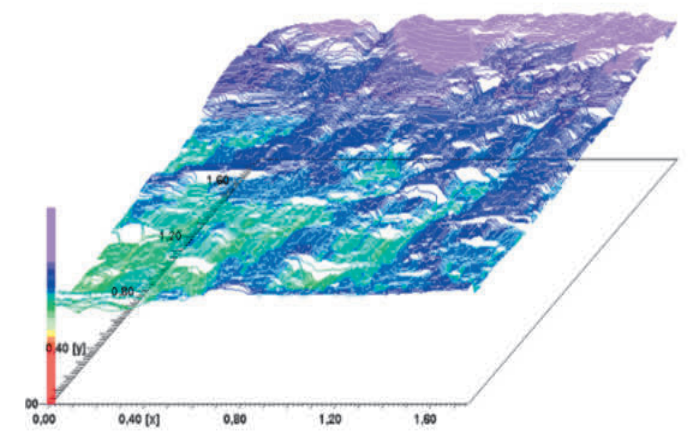

B

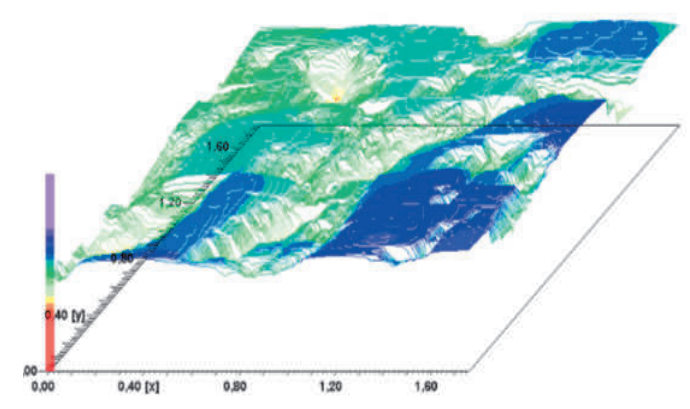

Figure 3 Surface topography of tested links: A- in initial state, B- after vibro-abrasive machining

Table 1 The average values of the basic parameters of roughness; A- links in initial state, B- links after vibro-abrasive machining

\begin{tabular}{|c|c|c|}
\hline Roughness parameters & A & B \\
\hline $\operatorname{Ra}[\mu \mathrm{m}]$ & 6.82 & 2.26 \\
\hline $\operatorname{Rv}[\mu \mathrm{m}]$ & 54.90 & 42.12 \\
\hline $\operatorname{Rp}[\mu \mathrm{m}]$ & 41.74 & 28.63 \\
\hline
\end{tabular}

\subsection{Hardness measurement}

The hardness measurement was carried out using Vicker's mthod acc. to ISO 6507 [10]. The measurement HV 0.025 was made for the zinc coating, the HV 10 for the steel core. The results of hardness measurement are shown in Figure 4. 

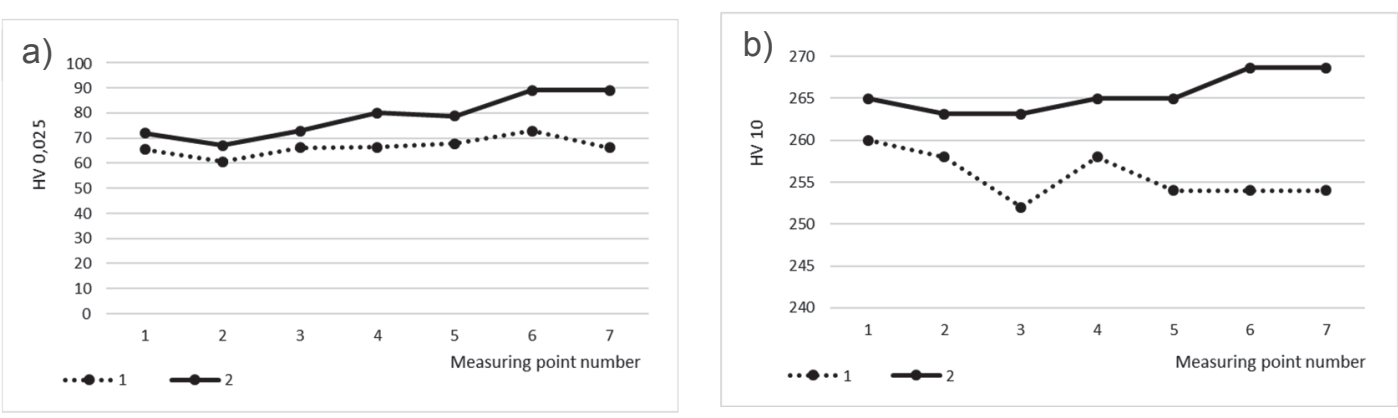

Figure 4 The hardness measurement results: a- for zinc coating HV 0.025, b- for steel core $41 \mathrm{Cr} 4$ grade HV 10

\subsection{Metalographic tests}

Metallographic examinations were made for all samples after hot dip galvanizing. Metallographic specimens were prepared in classic way. To microscopic observation the microscope Axiolmager M1m Carl Zeiss was used. Chosen results of observation the zinc coating microstructures are presented in Figure 5.
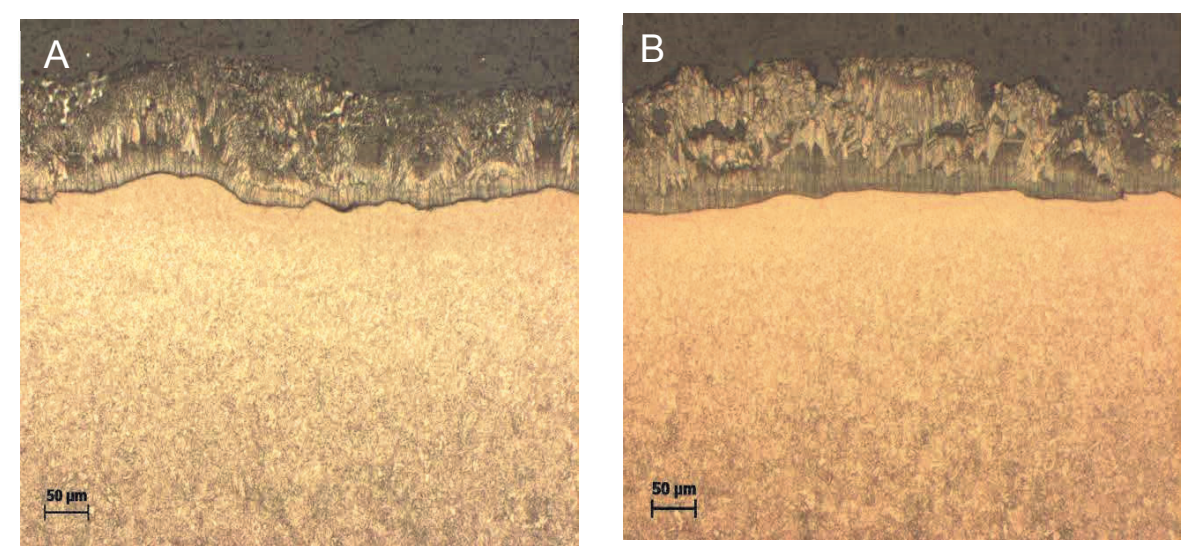

Figure 5 The microstructure of the zinc coating on links: A- in initial state, B- after vibro-abrasive machining

The measurement of Zn coating thickness was made according to ISO 1463 [11] for all samples. For links from Group A the average value of zinc coating thickness was $101 \mu \mathrm{m}$, for links from Group B it was $107 \mu \mathrm{m}$.

\subsection{Evaluation of the corrosion resistance}

The electrochemical research of corrosion resistance was conducted by use of a measurement system consisting of the Autolab 02 potentiostat produced by ECO CHEMIE B.V. company. Links were conditioned in the $3 \%$ solution of $\mathrm{NaCl}$.

The samples were tested using a potentiostatic method in the conditions of the open circuit potential (OCP). Duration of the test: $4 \mathrm{~h}$, after this time the potential value was stable. As a result, the average value from the last $30 \mathrm{~min}$ of the measurement was taken. The average values are presented in Table 2.

Table 2 The results of potentiostatic test; A- links in initial state, B- links after vibro-abrasive machining

\begin{tabular}{|c|c|c|}
\hline Parameter & A & B \\
\hline$E_{\text {corr }}[\mathrm{mV}]$ & -1016 & -982 \\
\hline
\end{tabular}

The samples were tested using a potentiodynamic method in the potential range of $-0.1 \mathrm{~V}$ to $0.1 \mathrm{~V}$ with a scan rate of $0.0017 \mathrm{~V} / \mathrm{s}$. The polarization started after 4 hours of establishing the stationary potential in the conditions 
of the open circuit potential (OCP). The electrodes were samples with zinc coating, the counter electrode was a platinum electrode and the reference electrode was an $\mathrm{Ag} / \mathrm{AgCl} 3 \mathrm{M} \mathrm{KCl}$ electrode.

On the basis of the conducted corrosion research it has been determined: the corrosion current density $I_{\text {corr }}$ $\left[\mu \mathrm{A} / \mathrm{dm}^{2}\right]$, and the following values were calculated: the corrosion potential $E_{\text {corr }}[\mathrm{mV}]$, measured from the minimum on the polarization curve and the polarization resistance $R_{p}[\Omega]$. The results, which were the average values, are presented in Table 3. The polarization curves in the corrosion solution are shown in Figure 6.

Table 3 The results of potentiodynamic test; A- links in initial state, B- links after vibro-abrasive machining

\begin{tabular}{|c|c|c|}
\hline Corrosion parameters & A & B \\
\hline Current density $I_{\text {corr }}\left[\mu \mathrm{A} / \mathrm{dm}^{2}\right]$ & 15.4 & 10.1 \\
\hline Corrosion potential $\mathrm{E}_{\mathrm{corr}}[\mathrm{mV}]$ & -1040 & -1007 \\
\hline Polarization resistance $\mathrm{R}_{\mathrm{p}}[\Omega]$ & 10.23 & 20.53 \\
\hline
\end{tabular}

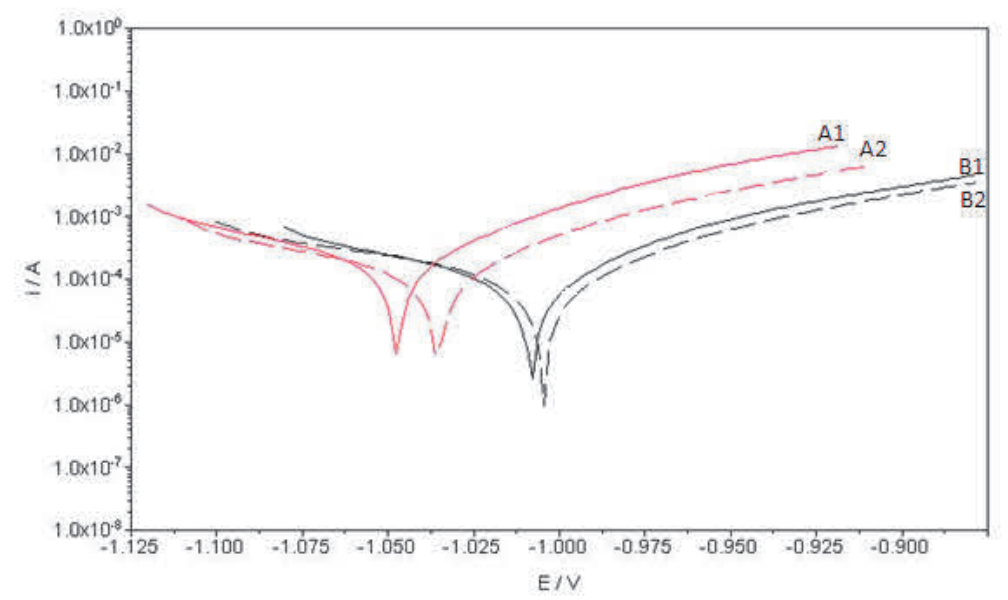

Figure 6 Example of polarization curves of links: A- in initial state, B- after vibro-abrasive machining; 1,2- number of sample

\section{RESULT DISCUSSION AND CONCLUSION}

The vibro-abrasive machining used for hot dip galvanized products improved the aesthetic qualities of the zinc coating. Sharp places and zinc burrs were removed. Tested treatment had positive effect on the surface roughness. The surface was smoothed and polished. Roughness parameters observed on the examined surface after additional treatment were lower than for samples in initial state. Ra parameter for links from Group B was $33 \%$ lower than for links from Group A.

The vibro-abrasive machining with the use of porcelain polishing fittings causes hardening of the substrate. The average value of the hardness measurement was $66 \mathrm{HV} 0.025$ for the links without machining, while for products after vibro-abrasive machining, about $20 \%$ higher.

The zinc coating thickness for all links was at a comparable level, $100 \mu \mathrm{m}$ for links from Group A, and $107 \mu \mathrm{m}$ for links after vibro-abrasive treatment, however, the additional treatment does not affect the zinc coating thickness. The microstructure of zinc coatings for the links of Groups A and B is also comparable. However, for links from Group B, inclusions and cavities are observed, which requires accurate identification and verification in future tests.

The thickness and structure of the zinc coating are factors determining corrosion resistance. Comparing the parameters values, i.e. current density $I_{c o r r}$, polarization resistance $R_{p}$, corrosion potential $E_{c o r r} z$ inc coatings 
after vibro-abrasive machining are proved slightly higher corrosion protection than zinc coating without additional treatment. Sample $B$ is slightly shifted towards the more positive values of the $E_{\text {corr }}$ potential, while the potential difference is lower than $50 \mathrm{mV}$, so it is insignificant.

On the basis of the conducted tests, it was found that vibro-abrasive machining technology is the right solution for hot dip galvanized forgings with centrifugation, especially in high volume production. The use of additional vibro-abrasive treatment after galvanizing improves aesthetic features of the products. Due to the similar value of the corrosion parameters for it may be assumed that vibro-abrasive machining of galvanized produts does not significantly reduce their corrosion resistance.

\section{REFERENCES}

[1] PN-EN ISO 1461 Hot dip galvanized coatings on fabricated iron and steel articles -- Specifications and test methods

[2] SCHULTZ, Wolf-Dieter and THIELE, Marc, General Hot dip Galvanizing. Materials - Technologies - Layer Formation - Properties - Defects. Bad Saulgau: Eugen G. Leuze Verlag KG, 2012.

[3] KUKLIK, Vlastimil and KUDLACEK, Jan. Zarove zinkowani. Praha: Asociate ceskych a slovenskych zinkoven, 2014.

[4] BAŃKOWSKI, Damian and SPADŁO, Sławomir. The Aplication of Vibro - Abrasive Machining for Smoothing of Castings. Archives of Foundry Engineering. 2017. vol. 1, pp: 169-173.

[5] BAŃKOWSKI, Damian, KRAJCARZ, Daniel, MŁYNARCZYK, Piotr. Deburring and smoothing the edges using vibro-abrasive machining. Procedia Engineering. 2017. no. 192, pp. 28-33.

[6] WOŹNIAK, Kazimierz and WINCENCIAK, Mariusz. Przygotowanie powierzchni detali pod powłoki malarskie metodą obróbki pojemnikowej. Lakiernictwo. 2014. vol. 94 no. 2, pp. 26-31.

[7] FILIPOWSKI, Ryszard and MARCINIAK, Mieczysław. Techniki obróbki mechanicznej i erozyjnej. Warszawa: Oficyna Wydawnicza Politechniki Warszawskiej, 2000.

[8] ISO 4287:1997 Geometrical Product Specifications (GPS) -- Surface texture: Profile method -- Terms, definitions and surface texture parameters

[9] ISO 13565-2:1996 Geometrical Product Specifications (GPS) -- Surface texture: Profile method; Surfaces having stratified functional properties -- Part 2: Height characterization using the linear material ratio curve

[10] ISO 6507-1:2018 Metallic materials -- Vickers hardness test -- Part 1: Test method

[11] ISO 1463:2003 Metallic and oxide coatings -- Measurement of coating thickness -- Microscopical method 